\title{
Detoxificating effects of moringa oleifera leaf and zingiber officinale root powder on cadmium toxicity in blood and fur of wistar rats
}

\begin{abstract}
The study was aimed at finding the detoxicating effects of moringa oleifera and zingiber officinale supplemented feeds in cadmium induced rats. 45 rats were divided into 9 groups of 5 rats and investigated for induced cadmium toxicity and detoxicating action of moringaoleifera $(\mathrm{Mo})$ leaf powder and zingiber officinale $(\mathrm{Zo})$ root powder on the fur and blood. Group 1, the normal control was fed with grower mash and water ad-libitum for 4 weeks; group 2, the negative control was induced with $0.5 \mathrm{mg} / \mathrm{bd}$ wt Cadmium nitrate solution and fed with grower mash and water ad-libitum for 7 days. Group 3-5 were induced with $0.5 \mathrm{mg} / \mathrm{bd}$ wt cadmium nitrate solution for 7 days and administered water ad-libitum and grower mash feed supplemented with 5\%,10\% and 15\% moringa oleifera leaf powder respectively for 21 days, group 6-8 were induced with $0.5 \mathrm{mg} / \mathrm{bd}$ wt cadmium nitrate solution for 7 days and was administered grower mash feed supplemented with $5 \%, 10 \%$ and $15 \%$ zingiber officinale powder respectively and water ad-libitum for 21 days. Group 9 was induced with cadmium nitrate solution for 7 days and administered with grower mash feed supplemented with 10\% mixture of moringa and zingiber powder for 21 days. The cadmium concentration in the fur and blood of the rats were analyzed using Atomic Absorption Spectroscopy (AAS). In the fur, the AAS results revealed that the supplemented groups of both biomaterials significantly $(\mathrm{P}<0.05)$ lowered the concentration of the heavy metal. In the blood, the AAS result showed that the concentration of cadmium was significantly $(\mathrm{P}<0.05)$ lowered by the supplemented groups in both biomaterials (Mo and Zo). This study reveals that the supplementation of feed with both plants led to a significant detoxification of cadmium and the detoxification ability increased with increased quantity of plant powder.
\end{abstract}

Keywords: AAS, cadmium, toxicity, ad-libitum, detoxicating
Volume 2 Issue I - 2018

\author{
Jangber ZN,' Ekwumemgbo PA, ${ }^{2}$ Okibe FG, ${ }^{2}$ \\ Oladele $\mathrm{SB}^{3}$ \\ 'Department of Veterinary Anatomy, Ahmadu Bello University, \\ Nigeria \\ ${ }^{2}$ Department of Chemistry, Ahmadu Bello University, Nigeria \\ ${ }^{3}$ Department of Veterinary Pathology, Ahmadu Bello University, \\ Nigeria
}

Correspondence: Jangber ZN, Postgraduate Research Student, Department of Veterinary Anatomy, Ahmadu Bello University, Zaria, Nigeria, Tel +2348175139024 ,

Email fellow4real55@gmail.com, pastorzaph@gmail.com

Received: November 10, 2017 | Published: February 07, 2018
Abbreviations: PCV, packed cell volume; WBC, white blood cell; AAS, atomic absorption spectroscopy; MO, moringa-oleifera; $\mathrm{ZO}$, zingiber officinale

\section{Introduction}

Heavy metals are hazardous substances that cause serious health risk to ecosystem and organisms due to their high toxicity conferred by nature of their environmental persistence. Heavy metals have been defined based on their specific density (of metals greater than 4 or $5 \mathrm{~g} /$ liter), having atomic weight between 63.546 and 200.590 (Sagakachi, Makajima \& Atoleiye et al). Unlike organic pollutants, heavy metals are non-biodegradable, so they persist for long in their host organism, constituting long term problem (Atolaiye). Cadmium is a soft, malleable, ductile, bluish-white divalent metal. It's average concentration in the earth crust is between 0.1 and $0.5 \mathrm{mg} / \mathrm{kg} \cdot{ }^{1,2}$ It is an environmental toxicant that adversely affect various organs such as liver, lungs, kidney, pancrease, testis, etc. ${ }^{3-4}$ Plants are said to contain some phytochemicals which are good potential chelating agents of heavy metals. ${ }^{5}$ Moriga oleifera is a vegetable belonging to the family Moringaceae which is widespread in both tropical and subtropical regions of sub-Saharan Africa. ${ }^{6}$

It is widely distributed in Asian countries, having a remarkable range of pharmacological properties in addition to significant nutritional values. The extract of Moriga oleifera leaves and other parts have been shown to have potent antioxidant actions. ${ }^{7-10}$ Zingiber officinale (ginger) is commonly used as food spice in many Asian and African countries including Nigeria. ${ }^{11}$ Zingiber officinale is one of the world's best spices and it has also been universally used throughout history for its health benefits. The main constituents include volatile oil, phenolic derivatives, Zingerone and Oleoresin (gingerols and shogaols are the main antioxidants compounds of the plant). ${ }^{12}$ Cadmium is one of most dangerous chemicals in the world's environment and humans are constantly exposed to cadmium through food, water, cigarettes and alcoholic beaverages. ${ }^{13-16}$ The aim of the study is to evaluate the effect of Moriga oleifera and Zingiber officinale Leaf powder in the detoxication of cadmium in Wistar rats.

\section{Materials and methods}

\section{Reagents}

All chemicals and reagents that were used were of analytical grades and were obtained from Stephmore Chemical Company, Zaria

\section{Collection and identification of plant materials}

The leaves of Moringa oleifera were obtained from Sabon Gari market, Zaria. The leaves were taken to the Herbarium of the Department of Biological Sciences, Ahmadu Bello University, Zaria, Kaduna State for authentication and voucher number (571) was deposited. The roots of Zingiber officinale were obtained from Sabon Gari Market Zaria and were taken to the Herbarium of the Department of Biological Sciences, Ahmadu Bello University, Zaria - Kaduna State for authentification and voucher number (2261) was deposited. 


\section{Animal feeds}

Grower mash which was used to feed the experimental rats was obtained from Samaru Market, Zaria. This feed was made into balls by addition of water and moulded into balls and dried under the sun. The rats were fed with dried moulded grower mash and water ad libitum.

\section{Experimental animals}

Sixty adult wistar rats weighing between $150.00-300.00 \mathrm{~g}$ were obtained from the Animal House of the Faculty of Pharmaceutical Sciences, Ahmadu Bello University, Zaria, Kaduna State. These were kept in the Animal House of the Department of Veterinary Anatomy, Faculty of Veterinary Medicine, Ahmadu Bello University, Zaria. The rats were kept for acclimatization for four weeks. Grower mash and water were administered ad libitum to the rats.

\section{The rats were divided into 9 groups of five rats each:}

Group 1: Positive Control (PC) - grower mash and water ad libitum.

Group 2: $\quad$ Negative Control (NC) - Cadmium nitrate+grower mash and water ad libitum.

Group 3: $\quad$ Cadmium Nitrate+5 \% Moringa oleifera supplemented feed+water ad libitum.

Group 4: Cadmium Nitrate $+10 \%$ Moringa oleifera Supplemented Feed+water ad libitum.

Group 5: $\quad$ Cadmium Nitrate $+15 \%$ Moringa Supplemnted feed+water ad libitum

Group 6: $\quad$ Cadmium Nitrate $+5 \%$ Zingiber supplemented feed+water ad libitum.

Group 7: $\quad$ Cadmium Nitrate $+10 \%$ Zingiber supplemented feed+water ad libitum.

Group 8: $\quad$ Cadmium Nitrate $+15 \%$ Zingiber supplemented feed+water ad libitum.

Group 9: $\quad$ Cadmium Nitrate+10\% mixture of Moringa and Zingiber supplemented feed+water ad libitums

\section{Preparation of Moringa oleifera and Zingiber officinale powder}

The Moringa oleifera leaves were washed with tap water and rinsed with distilled water. They were air dried at room temperature avoiding direct sunlight. When fully dried, the leaves were pounded using a wooden mortar and pestle and then sieved to fine powder, using $250 \mathrm{~mm}$ mesh. The powder was kept for use in a polythene bag and labeled. ${ }^{17}$ The Zingiber officinale roots were washed in tap water and then sliced into pieces and dried under the sun. When fully dried, it was pounded using a wooden mortar and a pestle and then sieved to fine powder using a $250 \mathrm{~mm}$ mesh. The powder was kept for used in a polythene bag and labeled. ${ }^{17}$

\section{Preparation of cadmium nitrate solution}

Stock solution of $250 \mathrm{mg} / \mathrm{kg}$ body weight was prepared by dissolving $2.50 \mathrm{~g}$ of cadmium nitrate in distilled water and making it up to the mark in a $250 \mathrm{~cm}^{3}$ standard volumetric flask using distilled water. ${ }^{18} 0.50 \mathrm{mg} / \mathrm{kg}$ body weight solution was prepared from the stock solution by serial dilution as in appendix 3.3. ${ }^{19}$ The volume to be administered to each rat was calculated using equation- $3.1 .{ }^{18}$

$$
\text { Rat dose }\left(\mathrm{cm}^{3}\right)=\frac{\text { Weight of rat } \times \text { Drug dose }}{\text { Stock solution }}
$$

This was administered intraperitoneally using syringe and needle.

\section{Preparation of Moringa oleifera and Zingiber officinale supplemented feeds}

Moringa oleifera supplemented feeds (5\%,10\% and 15\%) was prepared by weighing $5.00 \mathrm{~g}, 10.00 \mathrm{~g}$ and $15.00 \mathrm{~g}$ of Moringa oleifera leaf powder and uniformly mixing them with $95.00 \mathrm{~g}, 90.00 \mathrm{~g}$ and $85.00 \mathrm{~g}$ of grower mash respectively. These gave $5 \%, 10 \%$, and $15 \%$ Moringa oleifera supplemented feeds, respectively. ${ }^{11}$ Zingiber officinale supplemented feeds was prepared by weighing $5.00 \mathrm{~g}$, $10.00 \mathrm{~g}$, and $15.00 \mathrm{~g}$ of Zingiber officinale root powder and uniformly mixing them with $95 \mathrm{~g}, 90 \mathrm{~g}$, and $85 \mathrm{~g}$ of grower mash respectively. This gave 5\%,10\% and 15\% Zingiber officinale supplemented feeds respectively. ${ }^{11}$

\section{Preparation of mixture of Moringa oleifera and Zingiber officinale supplemented feeds}

Mixture of Moringa oleifera and Zingiber officinale supplemented feeds $(10 \%)$ was prepared by weighing $5 \mathrm{~g}$ of Moringa oleifera leave powder, $5 \mathrm{~g}$ of Zingiber officinale root powder, and $90 \mathrm{~g}$ of grower mash and mixing them uniformly, this gave 10\% mixture of Moringa oleifera and Zingiber officinale supplemented feeds.

\section{Results}

\section{Effect Moringa oleifera leaf supplementation in the cadmium concentration of the fur of rats}

The effect of Moringa oleifera leaf supplementation in the cadmium concentration of the fur of rats is presented in Figure 1. The results shows that the concentration of cadmium in the negative control group was significantly $(p<0.05)$ higher than the normal control, and all the treated groups. There was no significant ( $p>0.05)$ difference in the cadmium concentration of rats treated with $5 \%$, $15 \%$ Moringa oleifera leaf, and $10 \%$ mixture when compared to the control. However, the concentration was significantly $(\mathrm{p}<0.05)$ higher for rats supplemented with 5\% Moringa oleifera leaf when compared to the control and other treated groups.

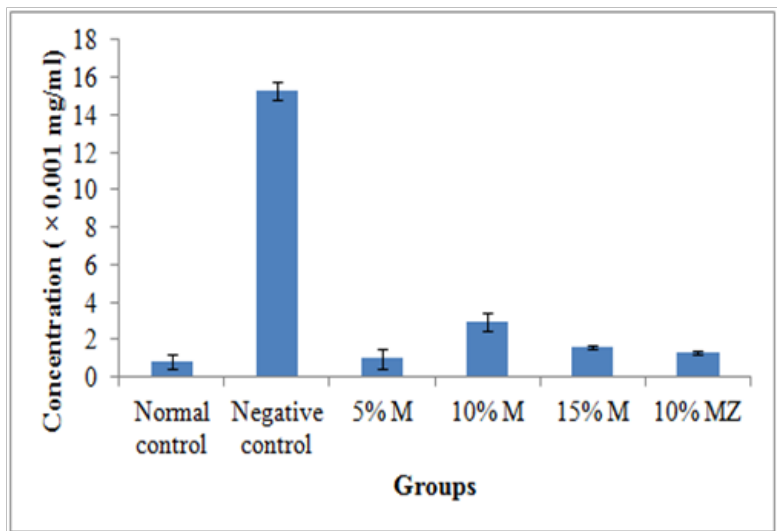

Figure I Effect Moringa oleifera leaf supplementation in the cadmium concentration of the fur of rats.

N: 5. 5\% M: 5\% Moringa oleifera, I0\% M: 10\% Moringa oleifera, I5\% M: 15\% Moringa oleifera, 10\% MZ: I0\% Moringa oleifera + Zingiber officinale 


\section{Effect Zingiber officinale leaf supplementation in the cadmium concentration of the fur of rats}

The effect of Zingiber officinale supplementation in the cadmium concentration of the fur of rats is presented in Figure 2. The results shows that the concentration of cadmium in the negative control group was significantly $(\mathrm{p}<0.05)$ higher than the normal control, and all the treated groups. There was no significant $(p>0.05)$ difference in the cadmium concentration of rats treated with 5\%,15\% Zingiber officinale leaf, and $10 \%$ mixture when compared to the control However, the concentration was significantly $(\mathrm{p}<0.05)$ higher for rats supplemented with 5\% Zingiber officinale leaf when compared to the control and groups treated with 10\% Zingiber officinale leaf and $10 \%$ mixture respectively.

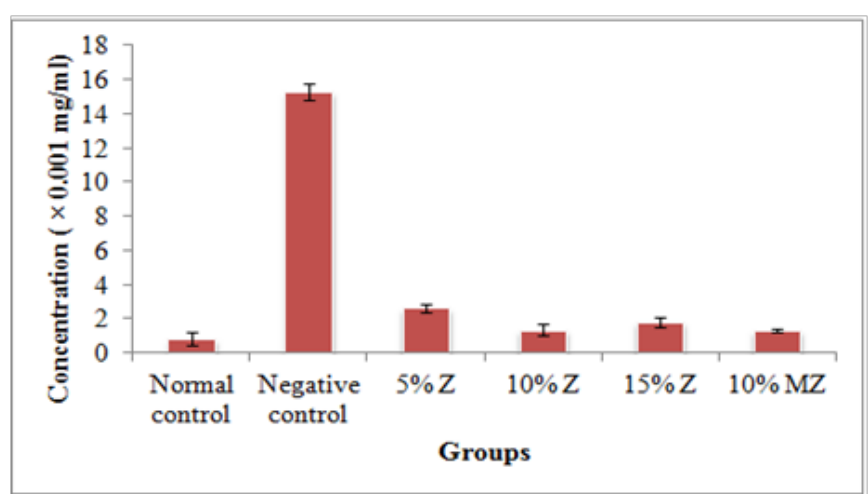

Figure 2 Effect Zingiber officinale supplementation in the cadmium concentration of the fur of rats.

N: $5.5 \%$ Z: $5 \%$ Zingiber officinale, 10\% Z: 10\% Zingiber officinale, 15\% Z: 15\% Zingiber officinale, I0\% MZ: I0\% Moringa oleifera + Zingiber officinale

Effects of Moringa oleifera supplementation in cadmium concentration in blood of wistar rats

The effect of Moringa oleifera leaf supplementation in the cadmium concentration of the blood of Wistar rats is presented in Figure 3. The results shows that the concentration of cadmium in the negative control group was significantly $(p<0.05)$ higher than the normal control, and all the treated groups. The concentration of cadmium was significantly $(\mathrm{p}<0.05)$ higher in the $5 \%$ supplemented group than $10 \%$ group which in turn was significantly $(\mathrm{p}<0.05)$ higher than $15 \%$ supplemented group. There was no significant difference $(\mathrm{p}>0.05)$ between $15 \%$ supplemented group and $10 \%$ mixture of Moringa oleifera and Zingiber officinale.

Effect Zingiber officinale powder supplementation on the cadmium concentration in the blood of wistar rats

The effect of Zingiber officinale supplementation in the cadmium concentration in the blood of rats is presented in Figure 4. The results shows that the concentration of cadmium in the negative control group was significantly $(\mathrm{p}<0.05)$ higher than the normal control, and all the treated groups. There is no significant difference $(p>0.05)$ among the treated groups.

Effect of Moringa oleifera leaf supplementation in the haematological parameters of cadmiun intoxicated Rats

The effect of Moringa oleifera leaf supplementation on the haematological parameters of cadmium intoxicated rats is summarized in Table 1. The result indicates that there was no significant ( $p>0.05)$ decrease in the haematological parameters of rats in the negative control group when compared to the normal control. Haematological parameters of rats supplemented with $5 \%, 10 \%$ and $15 \%$ of the leaves did not differ significantly ( $>0.05)$ from the negative control, except for white blood cell (WBC) count which was significantly $(\mathrm{p}<0.05)$ lower. Also, the haematological parameters of rats supplemented with $10 \%$ mixture did not differ significantly $(\mathrm{p}>0.05)$ from the positive and negative control groups respectively, except for the WBC count, which was significantly $(\mathrm{p}<0.05)$ lower than the negative control groups respectively.

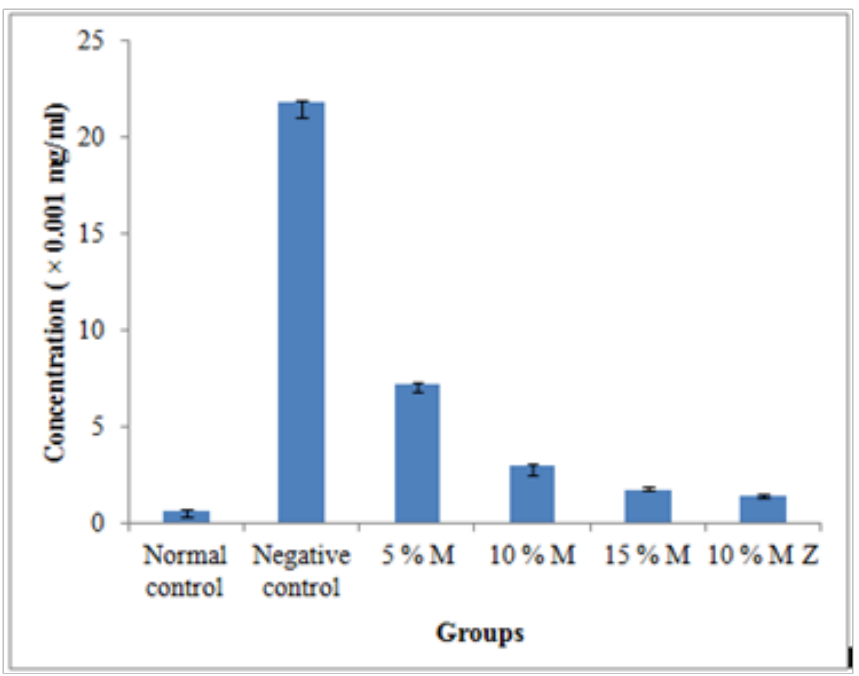

Figure 3 Effects of Moringa oleifera supplementation on cadmium concentration in blood of Wistar rats.

N: 5.5\% M: 5\% Moringa oleifera, I0\%M: I0\% Moringa oleifera, I5\%M: I5\% Moringa oleifera, I0\%MZ: I0\% Moringa oleifera + Zingiber officinale

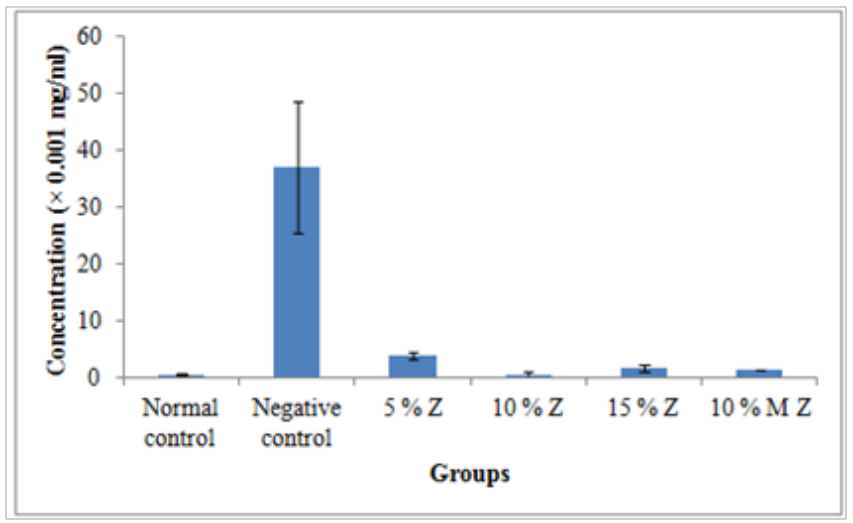

Figure 4 Effects of Zingiber officinale supplementation in the cadmium concentration in blood of Wistar rats.

N: $5.5 \%$ Z: 5\% Zingiber officinale, 10\% Z: 10\% Zingiber officinale, I5\% Z: I5\% Zingiber officinale, 10\% MZ: I0\% Moringa oleifera + Zingiber officinale

Effect of Zingiber officinale supplementation in the haematological parameters of cadmiun intoxicated rats

The effect of Zingiber officinale supplementation on the haematological parameters of cadmium intoxicated rats is shown in 
Table 2. The result indicates that there was no significant $(\mathrm{p}>0.05)$ decrease in the haematological parameters of rats in the negative control group when compared to the normal control except the packed cell volume $(\mathrm{PCV})$ which was significantly $(\mathrm{p}<0.05)$ lower. Haematological parameters of rats supplemented with $5 \%$ and $10 \%$ did not differ significantly ( $p>0.05)$ when compared to each other, and when compared to the positive and negative control, except for PCV WBC count which were significantly $(p<0.05)$ lower. Also, the haematological parameters of rats supplemented with $15 \%$, and $10 \%$ mixture did not differ significantly ( $>>0.05)$ from the positive control groups, except for the WBC count, which was significantly $(\mathrm{p}<0.05)$ lower than the positive and negative control groups respectively.

Table I Effect of Moringa oleifera leaf supplementation in the haematological parameters of cadmiun intoxicated rats

\begin{tabular}{lllll}
\hline Groups & PCV (\%) & HB (g/dl) & RBC $\left(\times 10^{12} / I\right)$ & WBC $\left(\times 10^{9} / I\right)$ \\
\hline Normal Control & $51.40 \pm 1.36^{\mathrm{b}}$ & $17.16 \pm 0.45^{\mathrm{b}}$ & $8.88 \pm 0.34^{\mathrm{c}}$ & $11.34 \pm 0.76^{\mathrm{b}}$ \\
Negative Control & $45.60 \pm 2.84^{\mathrm{ab}}$ & $15.20 \pm 0.93^{\mathrm{ab}}$ & $7.60 \pm 0.46^{\mathrm{abc}}$ & $11.14 \pm 1.36^{\mathrm{b}}$ \\
$5 \% \mathrm{M}$ & $35.40 \pm 2.36^{\mathrm{a}}$ & $11.88 \pm 0.76^{\mathrm{a}}$ & $5.90 \pm 0.41^{\mathrm{a}}$ & $8.46 \pm 1.69^{\mathrm{ab}}$ \\
$10 \% \mathrm{M}$ & $39.40 \pm 1.08^{\mathrm{a}}$ & $12.96 \pm 0.36^{\mathrm{ab}}$ & $6.44 \pm 0.16^{\mathrm{ab}}$ & $7.52 \pm 0.95^{\mathrm{a}}$ \\
$15 \% \mathrm{M}$ & $45.00 \pm 7.60^{\mathrm{ab}}$ & $13.52 \pm 2.91^{\mathrm{ab}}$ & $7.74 \pm 1.18^{\mathrm{bc}}$ & $6.96 \pm 0.78^{\mathrm{a}}$ \\
$10 \% \mathrm{MZ}$ & $51.60 \pm 1.69^{\mathrm{b}}$ & $17.18 \pm 0.57^{\mathrm{b}}$ & $8.64 \pm 0.28^{\mathrm{c}}$ & $5.62 \pm 0.80^{\mathrm{a}}$ \\
\hline
\end{tabular}

$\mathrm{N}: 6$. Values are presented as Mean \pm SEM. Mean with different superscripts down the column are significantly ( $\mathrm{p}<0.05)$ different. $5 \%$ M: $5 \%$ Moringa oleifera, 10\%M: 10\% Moringa oleifera, I5\%M: I5\% Moringa oleifera, 10\%MZ: 10\% Moringa oleifera + Zingiber officinale

Table 2 Effect of Zingiber officinale supplementation in the haematological parameters of cadmiun intoxicated rats

\begin{tabular}{lllll}
\hline Groups & PCV (\%) & HB (g/d) & RBC $\left(\times 10^{12} / \mathbf{l}\right)$ & WBC $\left(\times 10^{9} / I\right)$ \\
\hline Normal Control & $51.40 \pm 1.36^{\mathrm{c}}$ & $17.16 \pm 0.45^{\mathrm{ab}}$ & $8.88 \pm 0.34 \mathrm{c}$ & $11.34 \pm 0.76^{\mathrm{b}}$ \\
Negative Control & $45.60 \pm 2.84^{\mathrm{b}}$ & $15.20 \pm 0.93^{\mathrm{ab}}$ & $7.60 \pm 0.46^{\mathrm{b}}$ & $11.14 \pm 1.36^{\mathrm{b}}$ \\
$5 \% \mathrm{Z}$ & $37.40 \pm 1.17^{\mathrm{a}}$ & $12.42 \pm 0.39^{\mathrm{a}}$ & $6.30 \pm 0.23^{\mathrm{a}}$ & $5.60 \pm 0.29^{\mathrm{a}}$ \\
$10 \% \mathrm{Z}$ & $39.00 \pm 1.05^{\mathrm{a}}$ & $13.00 \pm 0.37^{\mathrm{a}}$ & $6.64 \pm 0.05^{\mathrm{a}}$ & $6.58 \pm 0.41^{\mathrm{a}}$ \\
$15 \% \mathrm{Z}$ & $47.80 \pm 1.50^{\mathrm{bc}}$ & $22.08 \pm 5.74^{\mathrm{b}}$ & $8.14 \pm 0.24^{\mathrm{bc}}$ & $6.74 \pm 0.35^{\mathrm{a}}$ \\
$10 \% \mathrm{MZ}$ & $51.60 \pm 1.69^{\mathrm{c}}$ & $17.18 \pm 0.57^{\mathrm{ab}}$ & $8.64 \pm 0.28^{\mathrm{c}}$ & $5.62 \pm 0.80^{\mathrm{a}}$
\end{tabular}

$\mathrm{N}: 5$. Values are presented as Mean \pm SEM. Mean with different superscripts down the column are significantly ( $<<0.05)$ different. $5 \%$ Z: $5 \%$ Zingiber officinale, 10\%Z: 10\% Zingiber officinale, I5\%Z: I5\% Zingiber officinale, I0\%MZ: I0\% Moringa oleifera + Zingiber officinale

\section{Discussion}

In Figures 1-4, the results of AAS showed that the concentration of cadmium in both the Fur and blood was significantly $(\mathrm{P}<0.05)$ higher in the negative control than the normal control and all the supplemented groups in both biomaterials. ${ }^{11}$ In the fur, the AAS results revealed that the supplemented groups of both biomaterials significantly $(\mathrm{P}<0.05)$ lowered the concentration of the heavy metal. In the blood, the AAS result showed that the concentration of cadmium was significantly $(\mathrm{P}<0.05)$ lowered by the supplemented groups in both biomaterials $(\mathrm{Mo}$ and Zo) except for 5\% Moringa oleifera supplemented group that had a significantly $(\mathrm{P}<0.05)$ higher concentration of cadmium compared to the rest of the moringa oleifera supplemented groups. This suggests that at higher doses of both biomaterials, detoxification of heavy metals is probably more effective in both blood and the fur. The effect of both biomaterials supplementation on the haematological parameters of cadmium induced wistar rats as summarized in Tables 1 and 2 showed that there was no significant $(\mathrm{P}>0.05)$ difference in the haematological parameters of rats in the negative control group when compared to the normal control group in both biomaterials, except the packed cell volume (PCV) of the Zingiber officinale supplementation which was significantly $(\mathrm{P}<0.05)$ lower at $5 \%$ and $10 \%(37.40 \pm 1.17$, $39.00 \pm 1.05)$ Zingiber officinale.

The significant variation in the PCV of $5 \%$ and $10 \%$ Zingiber officinale supplementation may be suggestive of anaemic condition of some sort which may be caused by the biomaterial (Zingiber officinale) which seems to be nephrotoxic at higher doses. The insignificant changes $(\mathrm{P}>0.05)$ in the haematological parameters may be suggestive of the fact that the biomaterials, especially Moringa oleifera has no aneamic effect in the rats. ${ }^{20}$

\section{Conclusion}

Supplementation of animal feeds with Moringa oleifera leaf and Zingiber officinale root powder significantly decreased the concentration of cadmiun, and this was more effective with Moringa oleifera leaf at $15 \%$ supplementation.

\section{Recommendation}

i. Moringa oleifera leaf should be incorporated in the diet, especially for people predisposed to heavy metal intoxication

ii. Further studies should be done that would involve other heavy metals such as lead, mercury, and arsenic

\section{Acknowledgements}

None.

\section{Conflict of interest}

The author declares no conflict of interest. 


\section{References}

1. Wedepohl KH. The composition of the continental crust. Geochimica etcosmochimica Acta. 1995;59(7):1218-1232.

2. Leelavinthan P, Ramaligam P. Protective effect of Tetrahyhdrocurcumin on plasma lipids and lipoprotein in cadmium intoxicated rats. International journal of toxicology and applied pharmacology. 2013:313-340.

3. Stohs SJ, Bagachi D, Hassoun E, et al. Oxidative mechanism in the toxicity of chromium and cadmium ions. J Environ Pathol Toxicol Oncol. 2000;19(3):201-213.

4. Atef MM Aftia, Fatma AA Ibrahim, Noha A Abdel-Latif, et al. Protective effects of ginger (Zingiber officinale Roscoe) against cadmium chlorideinduced oxidative stress in the blood of rats. Journal of medicinal plant research. 2014;8(39):1164-1172.

5. Ojeaga I, Haruna HG, Tajudeen BL. Phytochemical and Antimicrobial Studies on Moriga oleifera leaves extracts. Toxicology and Food technology. 2014;8(1):39-45.

6. Isitua CC, Ibeh IN. Toxicological assessment of aqueous extract of Moriga oleifera and Caulis bambusae leaves in rabbits. Journal of clinical Toxicology. 2013;512:4.

7. Ashok KN, Pari L. Anti-oxidant action of Moriga oleifera Lam. (drumstick) against antitubercular drugs induced lipid peroxidation in rats. J Med Food. 2003;6(3):255-259.

8. Arabshahi DS, Devi V, Urooj A. Evaluation of antioxidant activity of some plant extracts and their heat, $\mathrm{pH}$ and storage stability. Food chemistry. 2007;100(3):1100-1105.

9. Verma AR, Vijayakumar M, Mathela CS, et al. Invitro and Invivo antioxidant properties of different fractions of Moriga oleifera leaves. Food Chem Toxicol. 2009;47(9):2196-2201.

10. Sreeelatha S, Padma PR. Antioxidant activity and total phenolic content of Moriga oleifera leaves in two stages of maturity. Plant Foods Hum Nutr. 2009;64(4):303-311.
11. Egwurugwu JN, Ufearo CS, Abanobi OC, et al. Effect of ginger (zingiber officinale) on cadmium toxicity. African journal of biotechnology. 2007;6(18):2078

12. Sarbaz IM, Inaam AM, Shang ZA. Ameliorative effect of the aqueous extract of Zingiber officinale on the cadmium- Induced Liver and Kidney Injury in Females rats. Jordan Journal of Biological Sciences. 2013;6(3):231-234.

13. Jarup L. Hazards of heavy metal contamination. $\mathrm{Br}$ Med Bull. 2003;68:167-182.

14. Mead MN. Cadmium confusion. Do Consumers need protection? Environ Health Perspect. 2010;118(12):528-534.

15. Tamana T. Biochemical Estimation of Three Primary Metabolites from Medicinally Important Plant Moringa Oleifera. International Journal of Pharmaceutical Sciences Review and Research. 2011:7(2).

16. Wood CM, Farrell AP, Brauner CJ. Fish Physiology: Homeostatasis and Toxicity of Essential Metals. Academic Press, 2011. p. 125-184.

17. Aissi KA, Casimir DA, Julien S, et al. Attenuation of moringa oleifera leaves powder on blood biochemical disturbance induced in lead exposed rats. International Research Journal of Biological Sciences. 2016;5(1):14-21.

18. Haward CA. Pharmaceutical Calculations. 13th ed. China: Wolters Kluwer Health/Lippincott Williams and Wilkins; 2010.

19. Akawu I, Silas AE. General Laboratory Techniques and Organization Nigeria: ABU Press Limited Zaria; 2014.

20. Ajibade TO, Olayemi F, Arowole ROA. The haematological and biochemical effects of methanol extract of the seeds of moringa oleifera in rats. Journal of Medical Plants Research. 2012;6(4):615-621. 